\title{
English Acquisition as Second Language by Two English Major Students in China
}

\author{
Yun Deng \\ Foreign Language Department, Jiangxi Science and Technology Normal University, China
}

11577255@qq.com

Keywords: interlanguage, acquisition process, morpheme, emergence criterion

\begin{abstract}
This paper aims at analyzing the acquisition English learning in case study. In the study, two students are asked to do some sound records. And the study concentrates on these sound records. In addition, interlanguage and emergence criterion are two important theories in the research of the second language acquisition, and they are used to analyze the sound-recording, so as to give a more effective guide to the better command of people's second language acquisition.
\end{abstract}

\section{Introduction}

It is observed that extensive discussion and study of second language acquisition (SLA) implemented by foreign application linguists was not flourished until 1970s. It is widely believed that interlanguage plays a crucial role in applied linguistics and SLA. Many scholars and researchers at home and abroad have paid their attention to the theoretical and empirical study of how the interlanguage in one's mind participates in his acquiring a L2 where they made remarkable achievement. But if concentrating on the learners and the acquisition process, Selinker's interlanguage theory and Pienemann's emergence criterion (EC) are two inevitable theories that should not be overlooked.

In recent years, researchers have formed the consensus that more emphasis should be put on English speaking. The author found that one noticeable factor which leads to oral errors in Chinese college students is the negative command of interlanguage. But to what degree the negative transfer errors influence their oral production and what types of errors are caused by L1 interference remains uncertain. Only oral investigation can reveal these important facts. So the author decided to do a research on interlanguage which affects college students' oral English by conducting a case study on third-year English majors of Jiangxi Science \& Technology Normal University.

The major purpose of the study is trying to present the English learners or even teachers a clearer picture of the English major students' oral competence of Jiangxi Province after analyzing the errors they made in oral production by using EC. Based on the wildly accepted interlanguage theory and EC, the author hopes to find out how Chinese influences oral English speech and provide some practical suggestions to expect that students can manage to have a better command of English comprehensively. In this sense, the present study is of great necessity and practical significance as well as novelty.

\section{Review of Second Language Acquisition Theories}

The study of SLA provides a body of knowledge by which teachers can evaluate their own pedagogic practice and language learners can find a better way to acquire language.

\subsection{The Theoretical Background of Interlanguage}

(i) The Definition of Interlanguage

Interlanguage is the term coined by Selinker [1] to refer to the systematic knowledge of a second language which is independent of both the learner's first language and the target language. In his 
study, Selinker confirmed that this term contained two different but closely linked concepts of static and dynamic: One is the internal system set up by language learners in the process of second or foreign language acquisition in one certain stage. The other is known as Interlanguage Continuum.

(ii) The Development Process of Interlanguage

Ellis [2] says that it is a popular belief that SLA is strongly influenced by learner's first language, namely mother tongue. But in the second language acquisition, learners construct an abstract system of rules of language as the basis of understanding and generating a second language. This rule system is viewed as a Mental Grammar, i.e. the interlanguage.

The starting point of interlanguage becomes a major issue when SLA is seen as a recreation continuum rather than a restructuring continuum. Ellis, however, argues that there is no need to posit that the learner remembers early acquisitional stages. The starting point consists of the early vocabulary that the learner has acquired. This is used in non-grammatical utterances, and conveys the learner's meaning with the help of information supplied to the listener by the context of situation.

\subsection{The Theoretical Background of Emergence Criterion}

(i) The Definition of Emergence Criterion

In the study of language acquisition, acquisition criterion is an extremely important issue that can not be avoided. For it involves the conclusion of acquisition research, for example, whether acquisition is successful, logical and what does the acquisition sequence like, etc. EC is a better approach to the language acquisition research. Generally speaking, based on psycholinguistic theory, EC can provide a good point in observing and describing, so as to achieve the interpretation of interlanguage in its development from emergence to mastery.

(ii) The Development Process of Emergence Criterion

With the increasing emphasis on the L2 learner himself and his whole acquisition process in the SLA research, EC has been adopted to this kind of study. The researchers believe that the observation on interlanguage should not wait until the interlanguage system grows mature, but should observe it since it originates and watches its development of starting, growing and becoming mature. Therefore, the first attempt of the L2 learner or the initial second language component in his language usage is seen as the beginning of acquisition.

It is certain that the acquisition criterion is important in this study. Its main role lies in the identification of the time when the target language grammar becomes involved in the grammar system of interlanguage. In other words, the core issue of emergence criterion is when the grammar acquisition started.

\section{Research Design and Analysis}

In view of the above situation, the author of this thesis is trying to conduct a tentative study in this aspect to see how this kind of vocal systems influences oral English speech. This research aims to look into the emergence in terms of morpheme analysis and the rate of recurrence in college English majors' oral expressions. Quantitative approach and qualitative approach are both applied to analyze the data obtained in the research.

\subsection{Informants}

The two informants were chosen from English department of Jiangxi Science \& Technology Normal University, whose names are Zhangwenjun (Female) and Liulei (Male). They were both juniors and started to learn English since the first year of their middle school. Informant Zhang ranks in top ten of her class and has passion on English speech in particular. And informant Liu ranks in about top twenty of his class. The author chose these two students for the concern that they are two relatively typical examples which can represent common English majors. In this case study, they were asked to finish four oral tasks and do the sound-recording, and they really showed great interest. 


\subsection{Data Collection}

In this study, the two informants were asked to talk about three topics and the author recorded it and then did the morpheme analysis to analyze their L2 acquisition process. And the three tasks are respectively (1) talk about your hobby; (2) talk about your future plan and how you will achieve it; (3) talk about one of your travel experiences. Each of the tasks is started as soon as they saw the topics. In Task 1 the singular form “-s/-es" was focused in this task. Task 2 asked informants to describe their future plan and ways that may help to achieve it. And the plural form was focused this time for the study of morpheme of plural. Task 3 was to say something about one of their travel experiences. When the informants had to speak out their past experience, mounds of past tense were likely to emerge.

The three morpheme forms -the singular form, the plural form and past tense are three very common forms in English. So these forms were chosen to help finish the study so as to have a better acknowledge of language transfer in second language acquisition.

\subsection{Data Analysis}

After relistening and transcribing the data, the author has accounted the rate of recurrence of the three morpheme forms and the number of suppliance in obligatory contexts. One thing that deserves to be mentioned is that if a word like "is" was repeated in the informants' expression while there should be "was", then this kind of phenomenon was accounted as two tokens instead of one.

In this study EC was widely used as a kind of scientific method to present the acquisition stage, for it can present the learners' current state of linguistic rule system [3]. Without such criteria it would be impossible to test the stages in SLA. EC is on the basis of "systematic" and "productive" to determine the beginning of acquisition process [4]. In order to achieve "systematic", we will take Task 3 for instance. That is to say, if the informants said "determined", "built”, "said”, "taught” in one of his/her topic presentation, that means the acquisition of past tense for the learners is "systematic". For "productive", we may take Task 2 for an example. So in the topic of talking about one's future plan, the first informant begins with "plans" and she keeps saying "plans" afterwards, then we did not take it as a token of plural form, because it may just be her habitual usage, at the same time, she did talk about more than one plan in her oral expression. But for the boy, the second informant, he says "problems”, "minds”, “years”, and we call it "productive”.

And in order to reflect the data more exact and precise, the author gives two tables bellow to expressively describe the acquisition process in the form of emerging.

Table 1: The words and length of time for each task

\begin{tabular}{lcccc}
\hline \multicolumn{3}{c}{ Informant A: Zhang Wenjun } & \multicolumn{3}{c}{ Informant B: Liu Lei } \\
\hline \multicolumn{1}{c}{ Tasks } & Words & Length of Time & Words & Length of Time \\
\hline Task1 Hobby & 875 & $06: 21$ & 642 & $05: 30$ \\
Task2 Future Plan & 624 & $06: 19$ & 457 & $06: 04$ \\
Task3 Travel Experience & 862 & $07: 13$ & 753 & $07: 14$ \\
\hline Total & \multirow{2}{*}{4213} & $33: 41$ & &
\end{tabular}

This table describes the numbers of words and the length of time of each task. For each task, it is different from one to another. And from the table we can see that the most productive period happens in Task1 by informant A, with a total 875words. Though informant B used almost the same time as A, but his words only get to 457, far lesser than A's 624. The total words of this recording are 4213 and lasted for nearly 33.5 minutes. 
Table 2: The Result of Using the Three Morphemes

\begin{tabular}{lllllll}
\hline & \multicolumn{3}{l}{ Informant A: Zhang Wenjun } & \multicolumn{3}{l}{ Informant B: Liu Lei } \\
\hline Morphemes & $\begin{array}{l}\text { Obligatory Suppliance Percentage } \\
\text { Contexts }\end{array}$ & $\begin{array}{c}\text { Obligatory Suppliance Percentage } \\
\text { Colue }\end{array}$ & $\begin{array}{c}\text { Contexts } \\
\text { Value }\end{array}$ \\
\hline Singular-s/-es & 17 & 16 & $94 \%$ & 13 & 12 & $92 \%$ \\
Plural-s/-es & 19 & 12 & $63 \%$ & 13 & 6 & $46 \%$ \\
Past tense-ed & 54 & 33 & $61 \%$ & 39 & 16 & $41 \%$
\end{tabular}

Table 2 describes the proficiency results of using the three morphemes, the singular-s/-es, the plural-s/-es, and past tense -ed. From this table we can see that both the learners can manage the usage of the singular forms relatively well, with a more than $90 \%$ ratio. For the plural form, the ratio is $63 \%$ and $46 \%$. Informant A uses more plural forms and she can basically uses them well, but for informant B, the boy's performance turns out not that well. When it comes to past tense, both of them perform not very well, with the ratio of $61 \%$ and $41 \%$. And the ratio of this morpheme form happens to be the lowest of all the tasks for both informants A and B. And we may see that past tense -ed is perhaps a tense that is not that easy to master, at least not like singular form and plural form.

\subsection{Results and Discussion}

From the theoretical analysis of interlanguage we can see that interlanguage is a natural transition in language acquisition, but it still has some limitations: neglect the standards that the learners learn English himself, and the research methods are not complete enough. EC aims to determine the "emergence" of the rules of grammar, and then track their development process. So when in conducting the case study, the author combines interlanguage and EC together. And with the reference of EC, the limitations of interlanguage can be minimized so as to put forward to a more scientific research results.

Table 1 and Table 2 have given us a rather direct view of the acquisition stage of these specific grammars. And from the percentage value of these morphemes we can see that both of the informants showed a highest ratio, from which we can figure out that the learners must have mastered the singular forms quite well. The ratio in the plural forms happens to meet an intermediate level for both of the informants. And the ratio of past tense comes to the lowest. And these mean that perhaps the acquisition of past tense is difficult for the learners.

And an obvious error is that both the informants always forgot that they should keep in concord with tense in one sentence. That is to say, when it comes to a long sentence, the informants always started with a past tense but ended up with a present tense. Previously we have mentioned that interlanguage can be interpreted as an implicit knowledge of a second language system, as time goes on, learners will have to fix the system regularly. There is another detail which should not be overlooked, that is the learners' reconstruction, which means the restructuring of their interlanguage. For example when it comes to describe the buildings in Dalian in Task3, informant A firstly say "build" and then she realized her error and corrected it to "built" afterwards. Examples like this can be put forward a lot more but what the author wants to concern here is the acquisition restructuring in their interlanguage development.

\section{Conclusion}

SLA can be seen as a gradual acquisition process. The two informants are both juniors in English major, and their length of time in learning English almost hit nine years. From the sound-recording and the data analysis, we can see that the students still lack certain proficiency in their English learning. The emergence of these three sorts of morphemes have showed a great impact that 
interlanguage had on the SLA. And we can also find out that the best way for interlanguage to offer an active impact in SLA lies in the course of acquisition development from emergence to mastery [5].

It is obviously that English teaching in China is always grammar-oriented, that is to say, students are asked to learn lots of grammar rules and recite vocabularies by their English teachers. Few teachers and even the whole society seldom emphasize more on the practice of oral expression, which is actually the core issue to judge whether a learner has successfully mastered this kind of language. With this thesis, the author expect that some English learners can figure out the relationship between their native language and target language so as to facilitate their interlanguage acquisition process in an active way to achieve the real proficiency of English.

\section{References}

[1] Selinker Larry. Interlanguage. International Review of Applied Linguistics in Language Teaching [J]. 1972 10(3)209-213.

[2] Rod Ellis, M .Understanding Second Language Acquisition [M]. Shanghai: Shanghai Foreign Language Education Press,1994. 47, 70, 299.

[3] Pienemann, M. Language Processing and Second language Acquisition: Processability Theory[C]. Amsterdam: John Benjamin, 1998.145.

[4] Yanyin Zhang. A Review on Accuracy Criterion and Emergency Criterion. The International Chinese Teaching [J] ,2003(3) 52-60.

[5] Larsen-Freeman, D \& Long, M. An Introduction to Second Language Acquisition Research [M]. Beijing: Foreign Language Teaching and Research Press, 2000.48. 